\title{
Desain Interior Nahdlatul Ulama Jombang dengan Konsep Therapeutic Environment
}

\author{
Miftah A. Rahmati, Anggra Ayu Rucitra, dan Thomas Ari Kristianto \\ Jurusan Desain Interior, Fakultas Teknik Sipil dan Perencanaan, Institut Teknologi Sepuluh Nopember \\ (ITS) \\ Jl. Arief Rahman Hakim, Surabaya 60111 Indonesia \\ e-mail: anggra@interior.its.ac.id, thomasjawa@interior.ac.id
}

\begin{abstract}
Abstrak - Rumah Sakit Nahdlatul Ulama Jombang merupakan rumah sakit swasta kelas D yang didirikan oleh organisasi Nahdlatul Ulama di kota Jombang, Jawa Timur. Rumah Sakit Nahdlatul Ulama merupakan satu dari sekian banyak fasilitas kesehatan yang dibangun untuk memenuhi kebutuhan masyarakat atas pelayanan kesehatan. Tujuan utama rumah sakit adalah untuk mempermudah akses masyarakat untuk mendapatkan pelayanan kesehatan [1]. Dalam hal ini Nahdlatul Ulama ingin memasukkan pandangan islam terhadap praktek kesehatan dalam rumah sakit. Desain interior dari rumah sakit ini mengusung konsep therapeutic environment yang diharapkan dapat menciptakan efek yang baik bagi tubuh dan pikiran dalam proses penyembuhan penyakit. Konsep ini bertujuan untuk menunjang visi misi dari rumah sakit untuk menjadi pusat pelayanan kesehatan yang profesional dan islami. konsep therapeutic environment memiliki hubungan erat dengan psikologis manusia sebagaimana pengaruh sisi spiritual seseorang dalam proses penyembuhan. Metode penelitian yang digunakan dalam penentuan konsep desain yang akan dipilih ialah dengan metode kualitatif dan kuantitatif. Metode kualitatif dilakukan dengan melakukan pengamatan di lokasi objek terpilih yaitu Rumah Sakit Nahdlatul Ulama Jombang dan melakukan tanya jawab dengan beberapa orang yang memiliki kepentingan. Sedangkan metode kuantitatif dilaksanakan melalui kuisioner untuk mengukur tingkat harapan dan kepuasan pengguna terhadap objek desain. Pencapaian dari konsep therapeutic environment ini adalah ketika para pengguna merasa lebih nyaman dan tidak mengganggu bahkan menghambat proses pemulihan dan aktivitas lain yang dilakukan dalam rumah sakit. Selanjutnya pengguna akan memiliki tingkat kepercayaan terhadap pelayanan rumah sakit sehingga akan menggunakan jasanya dikemudian hari.
\end{abstract}

Kata Kunci-Islam, Rumah Sakit, Therapeutic Environment.

\section{PENDAHULUAN}

$\mathrm{K}$ ESEHATAN adalah keadaan keadaan sejahtera dari badan, jiwa, dan sosial. Kesehatan merupakan salah satu rahmat dan karunia dari Allah sebagai modal utama bagi umat manusia dalam menjalankan kehidupan. Kesehatan juga merupakan amanah yang wajib disyukuri dengan cara menjaga, memelihara, merawat dan memanfaatkannya untuk kepentingan-kepentingan yang diridhoi Allah SWT. Keberadaan fasilitas kesehatan berfungsi sebagai media pendukung dalam memenuhi amanah yang telah diberikan Allah demi mencapai kesejahteraan jasmani dan rohani. Rumah sakit sebagai institusi pelayanan kesehatan memiliki tujuan untuk mempermudah akses masyarakat untuk mendapatkan pelayanan kesehatan, memberikan perlindungan terhadap keselamatan pasien, masyarakat, lingkungan rumah sakit dan sumber daya manusia di rumah sakit, meningkatkan mutu dan mempertahankan standar pelayanan rumah sakit, dan memberikan kepastian hukum kepada pasien, masyarakat, sumber daya manusia rumah sakit, dan rumah sakit [1]. Rumah Sakit Nahdlatul Ulama Jombang merupakan institusi pelayanan kesehatan dari sistem kesehatan di Jombang. Rumah sakit ini dibangun dari sumber dana wakaf pengurus, warga dan simpatisan NU serta bantuan dari Pemerintah pada tahun 2009 hingga 2010. Saat ini rumah sakit kelas D ini mengalami kenaikan jumlah kunjuangan pasien yang menunjukkan meningkatnya kepercayaan masyarakat untuk menggunakan jasa pelayanan RSNU. Diharapkan untuk tahun yang akan datang status kelas RSNU akan berubah dari D menjadi C dengan pengembangan lahan dan pemenuhan fasilitas rumah sakit kelas C. Dengan meningkatnya perhatian dan kepercayaan yang didapat dari masyarakat, rumah sakit perlu melakukan penyesuaian dan pembenahan pada rumah sakit. Terlihat dari beberapa perubahan fungsi ruangan yang tidak direncanakan sejak awal sehingga menimbulkan ketidaknyamanan dan penghambatan aktivitas. Beberapa fasilitas rumah sakit masih kurang memenuhi standar dan kebutuhan pengguna. Desain interior dapat menjadi salah satu cara memaksimalkan potensi rumah sakit dan memenuhi kebutuhan pengguna. Sehingga dapat memenuhi tujuannya dalam mempermudah akses, memberi perlindungan dan meningkatkan mutu pelayanan kesehatan Pengambilan konsep therapeutic environment pada Rumah Sakit Nahdlatul Ulama Jombang adalah untuk menampilkan lingkungan yang berkontribusi pada pemulihan kesehatan pasien dan menghadirkan identitas rumah sakit pada desain interior. Sehingga suasana rumah sakit dapat memberi banyak manfaat dalam batasan konsep yang diaplikasikan, yaitu: therapeutic environment. 


\section{URAIAN PENELITIAN}

\section{A. Metode Pengumpulan Data}

Metode penelitian dalam proses perancangan desain interior Rumah Sakit Nahdlatul Ulama Jombang adalah metode kualitatif, yaitu metode yang bersifat deskriptif dan cenderung menggunakan analisis dengan pendekatan induktif. Untuk metode kuantitatif menggunakan kuisioner untuk mengukur tingkat kenyamanan pengguna dengan eksisting rumah sakit, sedangkan metode lain yang juga digunakan adalah metode analitis, dimana setiap data yang didapat akan dianalisis kembali.. Tahapan teknik pengumpulan data ini dilakukan dengan menggunakan metode observasi, penyebaran kuisioner dan studi literatur.

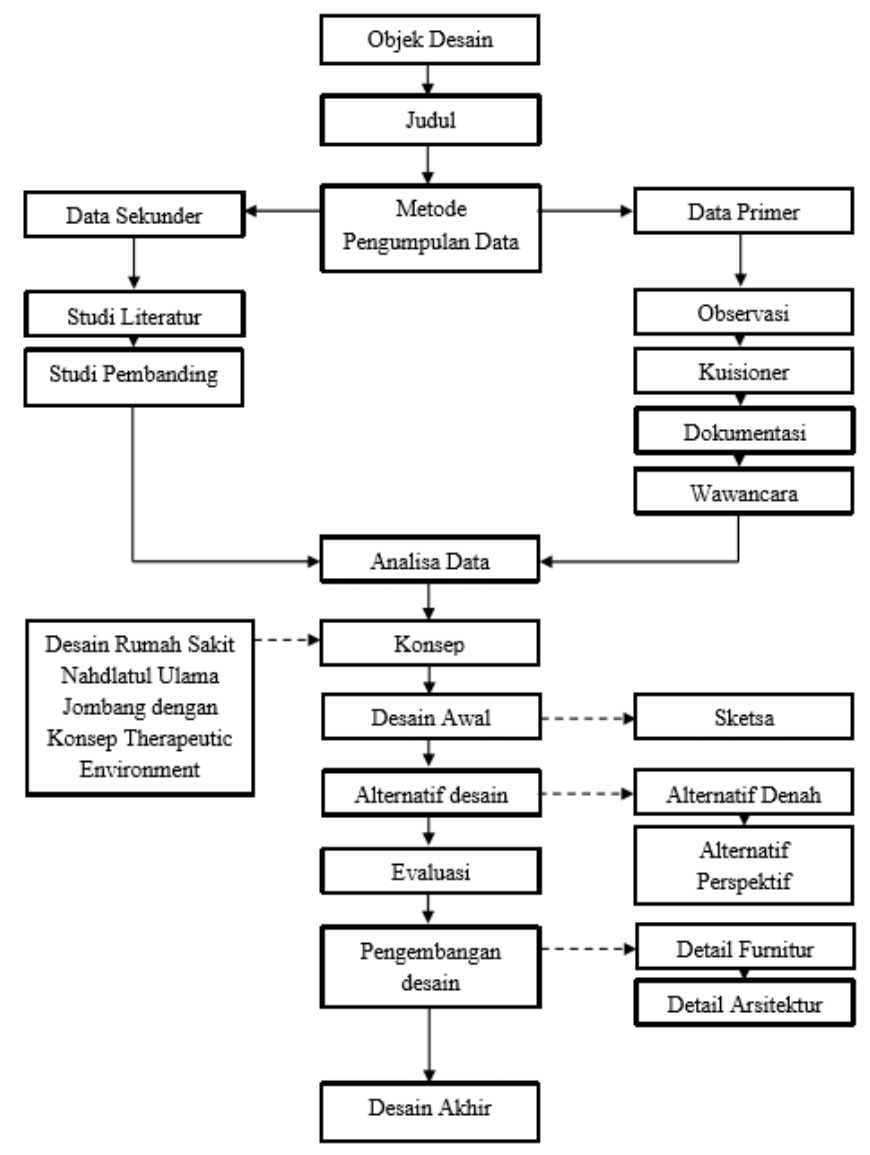

Bagan. 1. Skema Metodologi Riset Desain

\section{B. Metode Analisis Data}

Data yang diperoleh melalui studi wawanca, studi literatur dan observasi akan dikumpulkan dan diolah dengan memilahmilah data-data yang diproses lebih lanjut untuk dianalisis untuk dicari kesimpulan akhir atas pemecahan masalah yang ada dan sebagai acuan untuk proses perancangan.

\section{Metode Desain}

Data yang telah dianalisis kemudian diproses ke tahap perancangan. Tahap desain yang dilakukan adalah sebagai berikut: konsep desain, desain awal, evaluasi, pengembangan desain dan desain akhir.

\section{KONSEP DESAIN}

\section{A. Objek}

Rumah Sakit Nahdlatul Ulama yang beralamat di Kecamatan Ceweng Kabupaten Jombang Jawa Timur merupakan salah satu institusi pelayanan kesehatan sebagai bagian dari sistem kesehatan di Kabupaten Jombang. Rumah Sakit Nahdlatul Ulama adalah rumah sakit swasta yang berbentuk PT, dimana kepemilikan saham sebagian milik masyarakat. Rumah Sakit Nahdlatul Ulama diresmikan pada tanggal 10 Maret 2012.

\section{B. Konsep Makro}

Desain Rumah Sakit Nahdlatul Ulama Jombang memiliki konsep therapeutic environment yang disisipi unsur coorporate image lembaga pembangun rumah sakit yaitu Nahdlatul Ulama. Nahdlatul Ulama sendiri memiliki ikatan yang erat sekali dengan Islam. Perpaduan konsep ini dihadirkan ke dalam rumah sakit secara fungsi ruang dan tata ruang. Konsep makro terdiri dari elemen corporate image dan therapeutic environment. Elemen dari therapeutic environment itu sendiri ialah pencahayaan, warna, artwork, pemandangan, music, dan wayfinding [2].

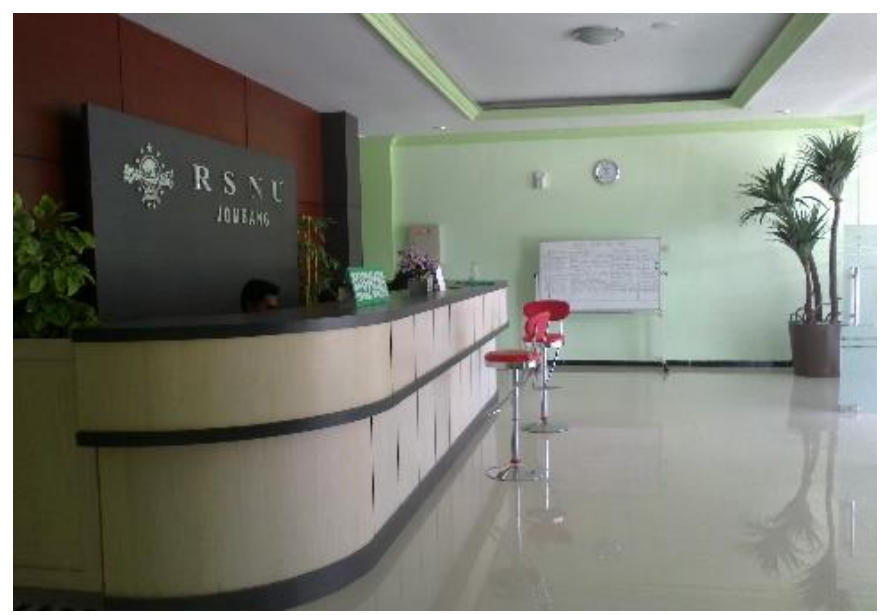

Gambar 1. Lobby Rumah Sakit Nahdlatul Ulama Jombang

Pencahayaan memiliki efek yang bermacam-macam bagi manusia salah satu efek yang paling jelas adalah memungkinkan manusia untuk melihat dan melakukan pekerjaa visual. Paparan cahaya juga berperan dalam sistem sirkadian tubuh agar sesuai dengan ritme aktivitas keseharian sehingga tubuh tidak lelah dan mengganggu aktivitas bahkan kesehatan. Paparan cahaya juga berupakan bagian penting dalam reaksi kimia dalam tubuh. Paparan cahaya menjadi satu-satunya cara untuk mengurai vitamin D dalam tubuh. Selain efek secara fisik, cahaya juga memiliki efek psikologis sehingga membuat banyak orang lebih senang memilik area kerja yang berada didekat jendela.

Warna dapat memberikan efek yang bermacam-macam, baik secara psikologi maupun fisik. Beberapa dari efek warna ialah, warna merah digunakan untuk merawat orang-orang dengan penyakit anemia, kelelahan, kelumpuhan dan kepayahan. Warna hijau menciptakan keseimbangan dan harmoni dalam tubuh. Warna ini terutama baik untuk masalah jantung dan darah. Warna ini diketahui mempengaruhi struktur sel dan otot 


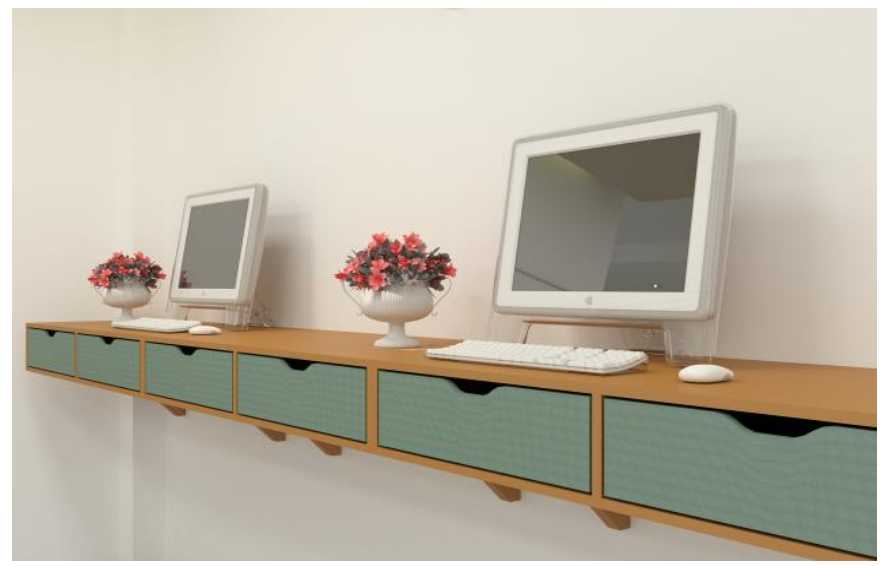

Gambar 4. Furnitur di IGD

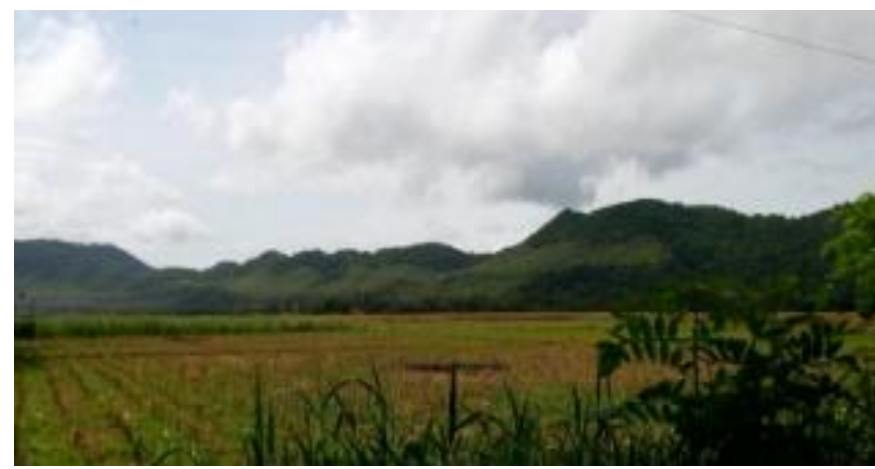

Gambar 2. Pemandangan alam

manusia. Dan Warna biru digunakan untuk kasus-kasus kondisi peradangan, luka bakar dan memar. Warna ini juga membantu eksim, psoriasis, ruam dan luka. Selain itu warna biru mebantu meringankan ketegangan, stress dan masalah dengan sistem kekebalan tubuh. Warna ini diyakini dapat meringankan insomnia, kecemasan, tekanan darah tinggi, migran dan iritasi kulit.

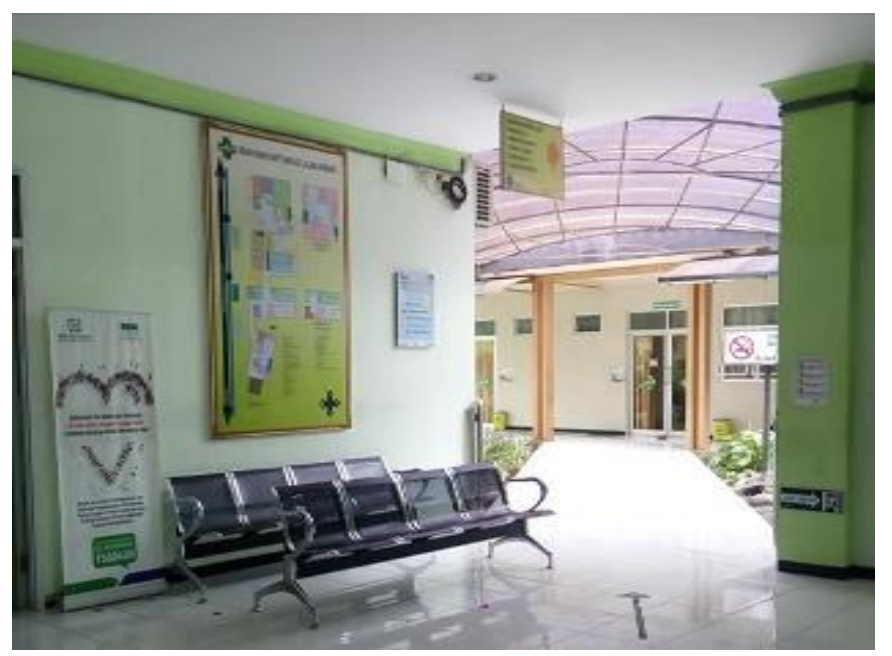

Gambar 3. Wayfinding di Rumah Sakit

Pemandangan dan seni memiliki fungsi utama untuk mengalihkan fokus para pengguna, baik fokus terhadap rasa sakit, stres, atau kegelisahan. Pemandangan keluar jendela berupa pepohonan, bunga, rumput, batu dan air (unsur alam) telah dibuktikan dengan penelitian yang kuat atas efeknya terhadap pasien dalam mengurangi stres dan kejenuhan.

Musik dapat menenangkan dan menciptakan suasana yang dapat menyemangati pasien dan pengunjung sedangkan wayfinding membantu dalam menciptakan lingkungan yang dapat dimengerti lebih mudah oleh para pengunjung

\section{Konsep Mikro}

1. Pencahayaan alami dan buatan

Pencahayaan alami baik untuk tubuh dan juga dapat mejalin kontak dengan dunia luar sedangkan cahaya buatan penting pada waktu malam hari dan cahaya akan merata pada ruangan 2. Warna hijau, natural, biru, peach

Warna natural tanah dan kayu diaplikasikan pada lantai untuk memberikan kesan alam dan hangat. Jika satu warna yang dapat digunakan (dalam kamar pasien) pada semua dinding, pilihan yang cocok adalah peach. peach disarankan untuk dermatologi, kebidanan, dan ginekologi. Gradasi warna biru dipilih karena menenangkan dan dapat diaplikasikan pada kasus-kasus kondisi peradangan, luka bakar dan memar. Gradasi warna hijau dipilih karena menciptakan keseimbangan dan harmoni dalam tubuh. Warna ini terutama baik untuk masalah jantung dan darah.

\section{Lantai vinyl}

Vinyl adalah pilihan ideal untuk lantai untuk sejumlah alasan.Vinyl adalah material non porous sehingga tidak ada penumpukan kotoran atau kuman. Ketika dipasang dengan benar tidak memiliki retak untuk menangkap kotoran atau kuman. Tepi mudah dilengkapi dengan penutup untuk menghindari sudut dan celah untuk bakteri. Mudah dibersihkan dan memungkinkan penggunaan bahan kimia yang tepat untuk membersihkan lantai agar lebih steril. Dapat berkereasi dengan warna dan motif. Selain vinyl lantai keramik juga diaplikasikan dalam rumah sakit, terutama pada daerah yang sering melakukan kontak dengan air seperti kamar mandi.

4. Dinding vinyl, keramik, partisi

Pengaplikasian vinyl pada dinding memiliki banyak keuntungan seperti halnya pada lantai. Penambahan elemen estetis seperti lampu hias, lampu malam, rak khusus untuk barang-barang personal pasien, bingkai foto, lukisan dapat memberikan kesan yang lebih familier dan menenangkan bagi para pasien dan pengguna. Dinding keramik juga diaplikasikan pada dinding yang sering melakukan kontak dengan air seperti halnya dinding kamar mandi.

\section{Plafon gypsum, hidden lamp}

Drop ceiling diaplikasikan pada ruang rawat inap untuk memberikan kesan yang tidak monoton dengan penambahan hidden lamp. Plafon yang dialikasikan ialah plafon bermaterial gypsum bewarna putih

6. Furnitur sederhana, natural dan elemen estetis.

Furnitur yang dipilih memiliki desain yang sederhana dengan garis-garis tegas dan mengaplikasikan finishing yang terlihat natural. 


\section{DESAIN AKHIR}

\section{Ruang Lobby}

Ruang terpilih 1 ialah area lobby dan apotek. Area lobby merupakan area publik bagi para pengunjung untuk mendapatkan informasi yang diinginkan melalui pegawai resepsionis, area ini juga memfasilitasi para pengguna yang akan membayar biaya operasional rumah sakit selama masa inap. Sedangkan area apotek memfasilitasi pengguna dengan area tunggu dan loket penebusan resep dokter.

Konsep therapeutic environment dihadirkan dalam area ini agar aktivitas menunggu tidak menimbulkan rasa tak nyaman sehingga pengguna akan lebih rileks, yang akan membantu dalam proses penyembuhan bagi pasien.

2. Ruang Rawat Inap

Ruang terpilih 2 ialah ruang rawat inap kelas 3. Ruangan ini merupakan ruang privat bagi para pasien yang sedang dalam proses penyembuhan dari penyakit yang dideritanya. Ruangan ini difasilitasi dengan 5 tempat tidur sesuai dengan ukuran ruangan. Konsep therapeutic environment dihadirkan dalam ruangan ini agar para pasien tidak mengalami kejenuhan, rasa tertekan, stress, bosan dan berbagai macam perasaaan yang dapat menghambat tubuh dalam menyembuhkan tubuh. Pemilihan warna yang diaplikasikan dalam ruangan ialah warna-warna natural seperti warna krem, putih dan hijau

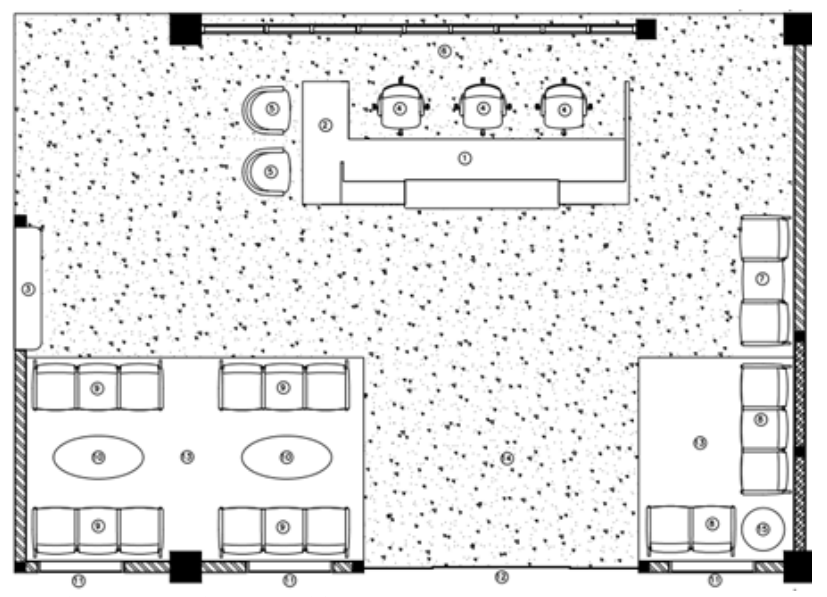

Gambar 5. Denah area Lobby

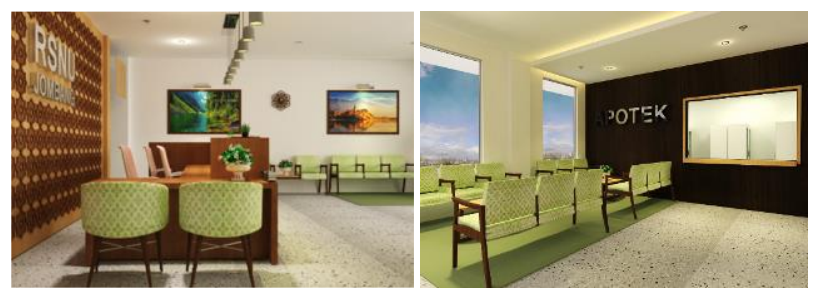

Gambar 6. view area Lobby (a) view area Lobby (b)

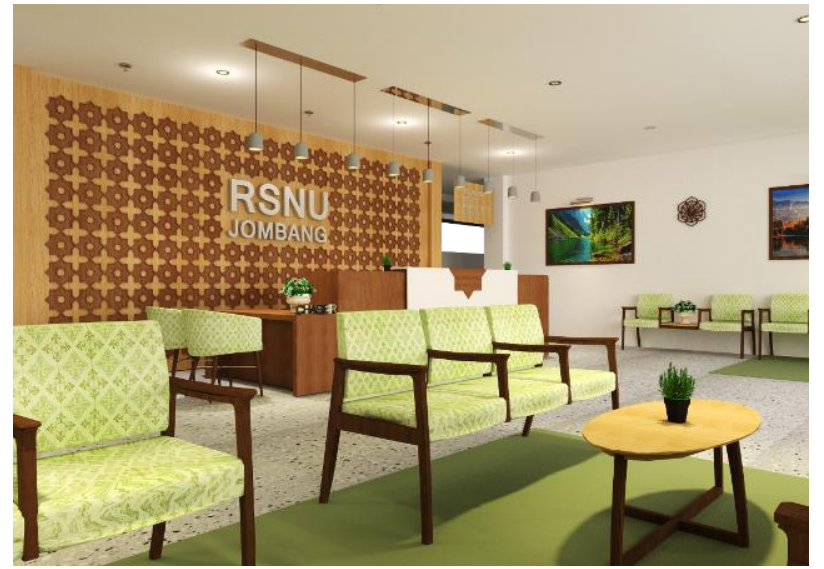

Gambar 7. Lobby dan ruang tunggu

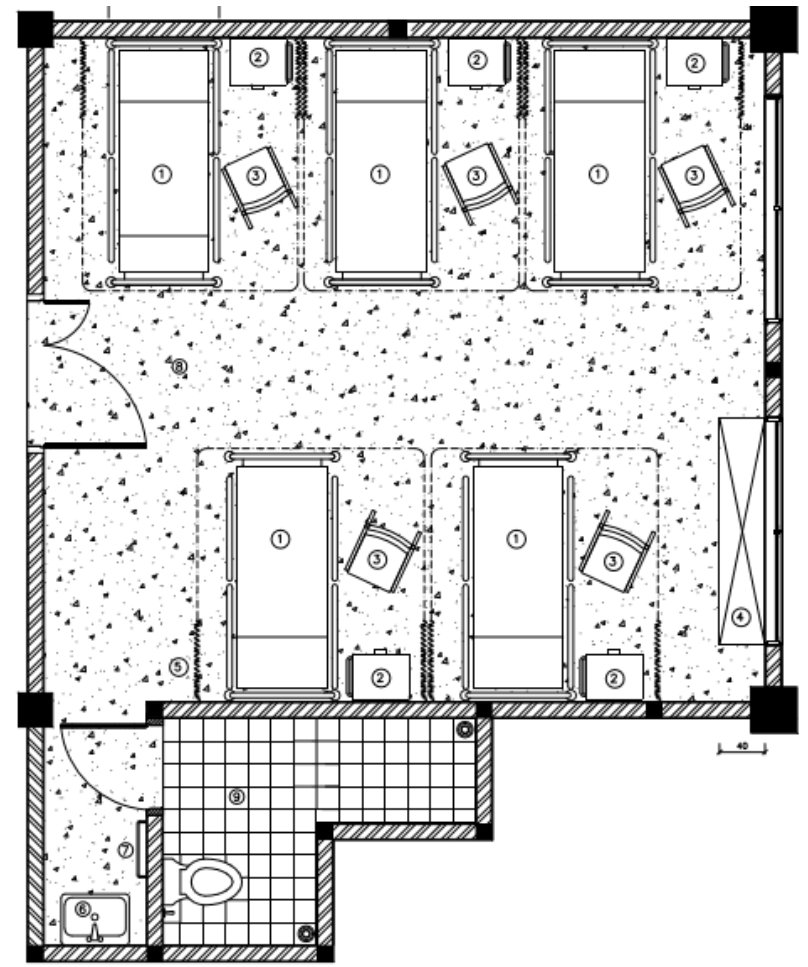

Gambar 8. Denah ruang rawat inap 


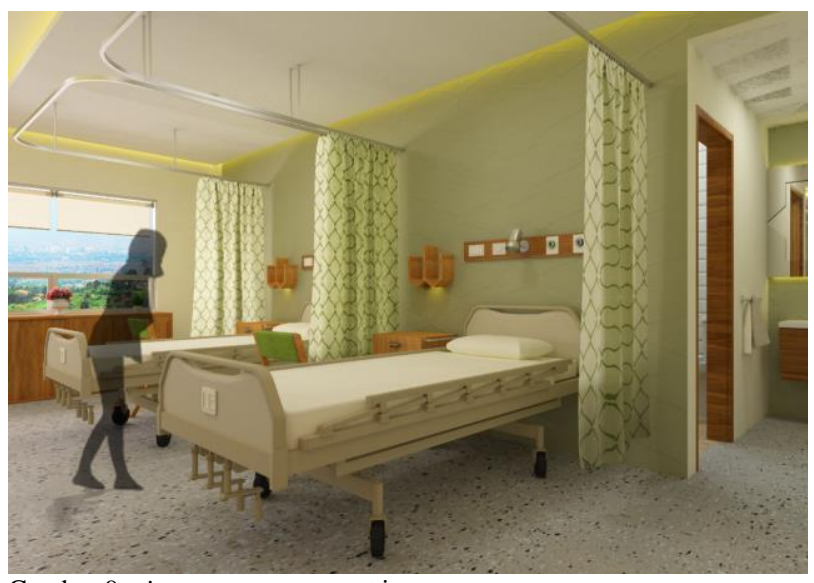

Gambar 9. view area ruang rawat inap

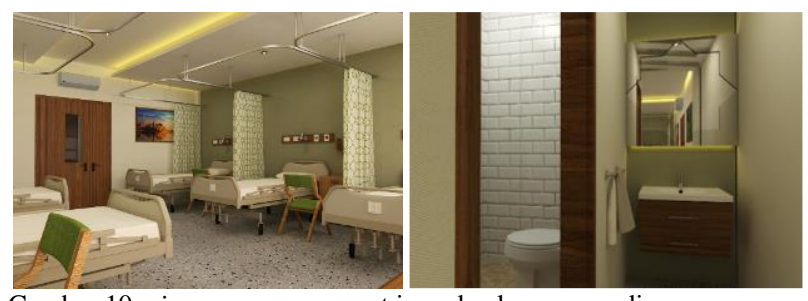

Gambar 10. view area ruang rawat inap dan kamar mandi

3. Instalasi Gawat Darurat

Ruang terpilih 3 ialah area IGD yang terdiri dari beberapa ruangan meliputi ruang tindakan, ruang penyimpanan, ruang istirahat dokter dan perawat dan resepsionis IGD. Area IGD ini difasilitasi dengan 6 tempat tidur, ruang penyimpanan obat, ruang istirahat dokter dan perawat, dan area resepsionis.

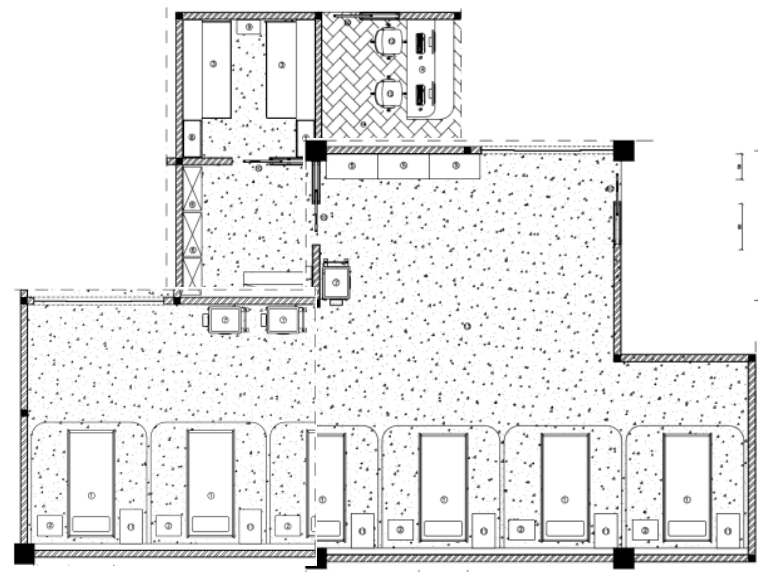

Gambar 11. denah area IGD

Area tempat penyimpanan obat memiliki 3 buah lemari dengan desain sederhana berwarna putih dengan rak-rak kaca di dalamnya. Dinding ruangan diberi warna putih dengan satu sisi diberi warna aksen hijau. Terdapat elemen estetis di dinding seperti dalam ruang istirahat dokter untuk menciptakan keselarasan desain. Ruang tindakan terdapat 6 buah tempat tidur beserta dengan nakas dan meja untuk keperluan makan dan menulis.

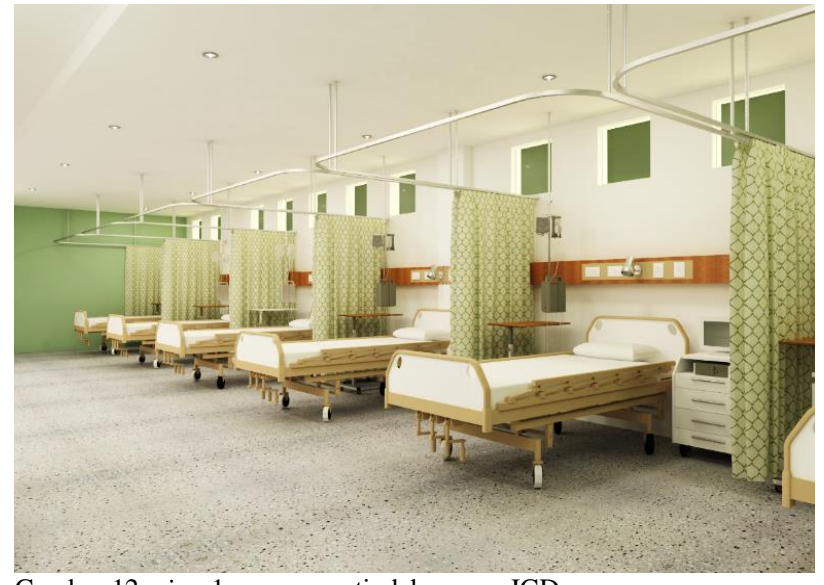

Gambar 12. view 1 area ruang tindakan area IGD

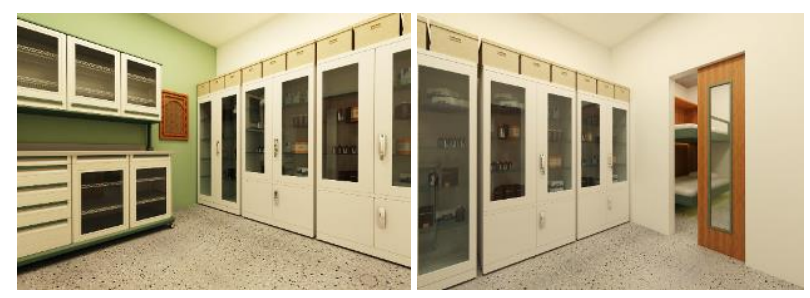

Gambar 13. view area ruang penyimpanan obat dan alat-alat (a) view area ruang penyimpanan obat dan alat-alat (b)

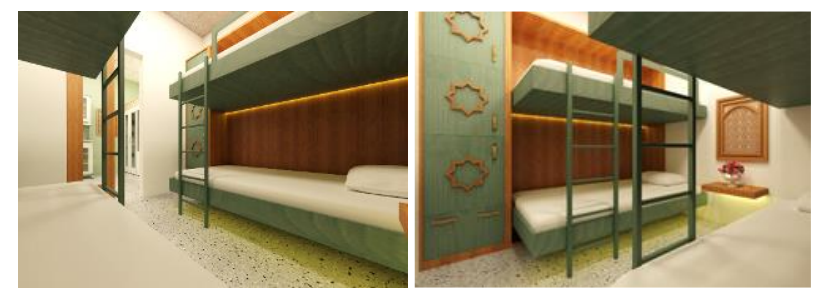

Gambar 14. view ruang istirahat (a) view ruang istirahat (b)

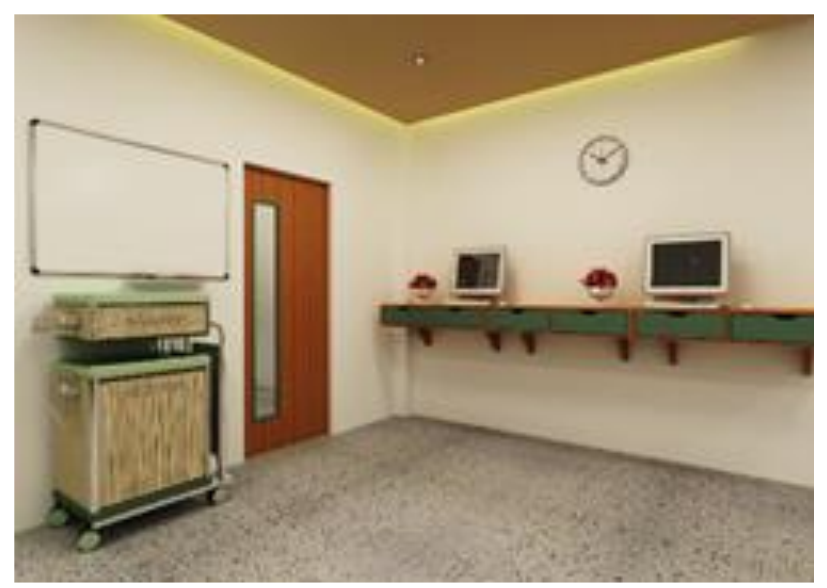

Gambar 12. view 2 area ruang tindakan area IGD

\section{KESIMPULAN/RINGKASAN}

Berdasarkan hasil pembahasan Desain Interior Rumah Sakit Nahdlatul Ulama Jombang dengan Konsep Therapeutic Environment, dapat diambil beberapa kesimpulan.

Mendesain sirkulasi rumah sakit tetap harus mengikuti standar peraturan yang dikeluarkan pemerintah. Penataan sirkulasi yang didasari dengan peraturan harus memudahkan 
akses pengguna baik pengunjung, pasien dan pegawai rumah sakit. Sirkulasi yang baik juga harus memperhatikan kebutuhan pengguna dan aktivitas yang dilakukan.

Desain wayfinding/signage juga sangat penting dalam rumah sakit agar para pengguna tidak tersesat dan stres. Desain wayfinding di berikan secara tulisan maupun dengan isyarat warna dan bentuk sebagai bahasa universal. Pengaplikasian corporate image dapat dilakukan dengan cara yang paling mudah adalah memasukkan unsur warna dan bentuk yang khas dari Rumah Sakit Nahdlatul Ulama. Selain itu memberikan pelayanan yang didasari dengan visi-misi dari rumah sakit dapat membentuk corporate image.

Konsep Therapeutic Environment yang diaplikasikan pada rumah sakit berasal dari beberapa elemen yaitu, pencahayaan, warna, artwork, pemandangan, wayfinding, dan musik. Pencahyaan baik alami maupun buatan memiliki dampak yang positif terhadap pengguna jika diaplikasikan dengan layak. Pemilihan warna disesuaikan dengan jenis aktivitas dan efek yang diberikan kepada pengguna. Pemberian artwork/seni juga memberikan rasa tenang yang dapat mengalihkan kegelisahan dan mengalihkan fokus dari rasa sakit begitu juga dengan efek pemandangan di luar jendela. Wayfinding yang jelas dapat mengurangi kegelisahan dan stres. Musik yang sesuai dengan aktivitas dapat memberikan rasa senang dan semangat

\section{DAFTAR PUSTAKA}

[1] Republik Indonesia. (2009). Undang-Undang Republik Indonesia Nomor 44 Tahun 2009 Tentang Rumah Sakit. Sekretariat Negara. Jakarta.

[2] Smith, R., and Watkins, N. (2016). Therapeutic Environment. Therapeutic Environments Forum, AIA Academy of Architecture for Health. [online].avsilable : https://www.wbdg.org/resources/therapeuticenvironments 